\title{
A Case Study: Study of Amman Stock Exchange Volatility during 1994-2013
}

\author{
Mohammad Alalaya ${ }^{1}$ \\ ${ }^{1}$ Al Hussien Bin Talal University-Ma'an, Jordan \\ Correspondence: Mohammad Alalaya, Department of Economic, Faculty of Administrative and Economics, Al \\ Hussein Bin Talal University-Ma'an, Jordan. E-mail: dr_alaya@yahoo.com
}

Received: January 24, 2014

Accepted: March 6, 2014

Online Published: April 24, 2014

doi: 10.5539/ibr.v7n5p80

URL: http://dx.doi.org/10.5539/ibr.v7n5p80

\begin{abstract}
This paper investigates the volatility of Amman stock exchange volatility during the period 1994-2013, also the paper focuses on the performance of various Garch models, were Arch model not dismissed in term of their ability of delivering volatility forecasts for Amman stock market return data, in this paper a stationary Garch models were estimated, I have assess the performance of the maximum likelihood estimator, finally I have attempt to fit the dynamic of daily Amman stock return, by different models and BL, approach. A quantified data of the returns of weekly dealing has been used to achieve the goals of paper, enhance the $(\gamma)$ leverage used to test for asymmetric volatility. This paper is an attempt to study and modules the volatility of Amman stock market using daily observations as the day-of-a week return index for the period from January, 1994 through the period up to end of June, 2013, to achieve this purpose I have divided the period of study into two periods, then I have estimated the data by using Arch (1), Garch, E Garch, and the Go-Garch models are employed.

Arch (1) and E-Garch models are utilized in this paper to have the symmetry effects, whereas E-Garch are used to capturing the asymmetric effect. Results can be stated as: the E-Garch model is most fitted model to forecasting data of returns volatility between Garch $(1,1)$ and $\operatorname{Garch}(1,2)$ as model performance is very small, according to BL approach Alpha of AMS portfolio and frontiers returns is $(-0.5492)$, and the risk ratio is (0.5683).
\end{abstract}

Keywords: Amman stock exchange, Garch and Arch models, BL approach, volatility leverage effects

\section{Introduction}

\subsection{Brief Notes}

ASE (Amman stock exchange) as any stock market in the development countries, it characterized by turnover ratio, it also has low liquidity, the non existence of market decision makers and the turnover ratio for the period under investigation was $14.62 \%$, also the average turnover approximately daily is $0.78835 \%$, this ratio is too few, and these respectively too small, the one of major action that might be effect trading activity. And the average daily turnover is ownership of individual investors and institutional, and government.

Table 1 shows the distribution of shareholder in ASE.

Table 1. Distribution of share holder in ASE

\begin{tabular}{ll}
\hline Owners & $\%$ \\
Foreigner & 4.2 \\
Arab citizens & 45.5 \\
Jordanian & 50.3 \\
Total & 100 \\
Individuals & 52.9 \\
\hline
\end{tabular}


The ASE has an increased in the number of listed companies through out the years, which reflex economic growth in Jordan, and stability during the period of 2003-2013 in ASE. The trading volume increased year to year, these results indicates of visibility of ASE is superior than other stock markets in middle east region, it has undergone accelerated growth especially during the last 6 years due to stability and the Arab holder shares such Iraqi investors, also Jordan government represented the board of international accounting standard. Some indicators of ASE, It established 1976 and it is emerging stock market, the capitalization is 9.765 million US dollars, and the change 1n 1999-2003 is 8.4\%, while it in 1998-2013 is $27.3 \%$, where the capitalization ratio to GNI is $57.45 \%$, where the turnover is $13.54 \mathrm{~m}$ us dollars, and the turnover (liquidity) is $19.26 \%$.

An efficient capital markets optimize the process of investment through which capital may be transferred from net savers to net borrowers, when this happens we can say that market is efficient, and the share prices must reflects all variables or available information which is relevant for the evaluation of company's future performance, and therefore share prices must be the rational explanation for future discounted profits.

Emerging markets in developing countries got more attention in recent years due to some factors which effects the growth of gross national product (GDP), such as the fast and quick grew of returns of trading volume, then increasing of number of listed companies in the emerging markets, also market capitalization. Many previous studies and researches fund a low correlation between developed and emerging markets, which made emerging markets interesting for portfolio diversification, thus the high returns is exceeded which obtain in emerging markets is associated how ever with high risk and high volatility and high autocorrelation, charistersic of time series such as the returns on stock indexes have a certain characteristics which explained in literature of study.

A "robust standard errors," has also reduced the concern over heteroskedasticity, according sample size, then robust standard errors gives precise estimate of standard errors, even with heteroskedasticity, due to small size of sample 1, it is important to have heteroskedasticity correction which does not effect the coefficients, but there is other useful for this processes.

\subsection{Previous Studies}

In this paper the goal of such models is to provide a volatility measures such a standard deviation that can be used in financial decisions concerning risk analysis, portfolio selection and derivative pricing. Engle (1982) used a model of time-varying conditional variance with auto-regressive conditional heteroskedasticity Arch (1) processes using lagged disturbances. Laurent, and lecourt (2000), utilized of student's distribution in their study. Aimed to capture skewness, and later extended to Garch model. Van der wide (2002) was used the GO-Garch model in his study and the orthogonal Garch model of Alexander (2001). Fan et al. (2008) studied a general version of the model by relaxing the assumption of independent factors to conditionally uncorrelated factors. For surveys on multivariate volatility models was refer to Bauwens et al. (2006) and for a glossary to volatility models.

The model (asymmetric) volatility spillovers that denoted multivariate of financial data. Moreover, the model is in linear transformation; also it is closed under temporal aggregation, which makes the model analytically convenient, as Hafner (2008). Van der Wide (2002) used two step estimation methods which requires a maximum likelihood (ML) estimation for parameters, both in linear transformation and in the univariate Garch specifications for the individual factors. The overall results are that Garch models are unable to capture entirely the deviations in volatility. A regression of volatility estimates from Garch models on actual volatility produces $\mathrm{R}^{2}$ usually below 8 percent, however, a positive note, the Garch prediction of volatility. The Garch models are not wholly inadequate measures of actual volatility.

My framework in this paper is relatively and closely related to the recent papers by Alexander (2001), lambert and Laurent also Andersen and Bollerslev (1998), Hafner (2008), Diebod and Ebens (1999) and Fan et al. (2008). Those papers shows that traditional tests of various volatility models which rely on ex-post squared returns as realized volatility are very noisy although an unbiased. Mackawa et al. (2005) proposed the Tokyo stock market returns data sets posses' volatility persistence, many cases a consequence of structural breaks is available in Garch process. Bauwens and Storti (2007) reported that often volatility goes up proportionally less after out laying shocks that it does after small and moderate shocks, to reduce the effect of outliers on the predicted volatility, my advocate in this paper of M-Garch, is where the effect of out laying returns on volatility predictions is bounded and also the Arch $(1,1)$ has been used and other alternative models of stochastic volatility are implied volatility models from option pricing are not at debate here, in addition, various and other measures of volatility based on volume, price range which effected volatility of return of Amman Stock market. 


\subsection{Organization of the Paper}

Finally this paper has organized as follows: section one contain introduction, where the second section briefly discussed of Arch model, and Garch models as a literature review of these important models in financial date estimation and the models of the study paper, section three discussed the data sources and methodology, sample tests are conducted on forth section, while section five presents out-of-sample performance is analyzed and the empirical results. Where section six conducted concluded remarks and references.

\section{Literature Review of Arch and Garch Model}

The purpose of forecasting volatility is to addressed risk management, asset allocation, and for taking bets on future volatility, the risk management is this field is measuring the losses of a portfolio of assets, this can be achieved by estimates of future volatility and correlations, a standard approach of Markowitz to minimizing risk of portfolio assets of it is of expected returns, in other hand in the field of risk measurement it is necessary to estimate variance - covariance matrix. The historical ST/Deviation used as an approach to estimate. an empirical notes to be observed of asset return of analyses as a result squired returns are positively autocorrelation, if an asset in Amman stock market like a currency, commodity, stock price, or bond price made a big move in a days ago, it made spike move up and downward. The Amman stock market crashed on November 2007, thus we can see anecdotally that moves of prices as Bollinger bonds limitations or Elliot wave analyses.

Volatility always spikes up during the period of financial crisis, sometimes it eventually slipped down as the same level of volatility or moderately as before crisis, it means that there are periodical spikes in volatility due to crisis that caused less returns. In the models we look we try to capture the autocorrelation of mean squared returns, as well as the excess kurtosis of squared returns. In this paper the first model I have used it is an Arch model, which represents autoregressive conditional heteroskedasticity. The conditional here comes through the model, next periods volatility is conditional on information this period heteroskedasticity means non constant volatility (if the variance of residuals is not constant), when we estimate the coefficients in the model by least square method (OLS), let us use Arch (1,1) model which developed by Engle (1982). We assume that returns on asset are:

$$
\sigma_{2 t}=a_{0}+b_{1} a_{2 t-1}
$$

Where $a_{0}>0$ and $b_{1} \geq 0$ to ensure positive variance and $b_{1} \geq 1$ for stationary through Arch (1) model, under the model estimate, if residuals returns, $a_{2 t}$ is greater than 0 , forecast for next periods conditional volatility, at +1 will be large, we can say in this state that the returns are conditionally normal, and the one period returns are normally distributed, and returns $\left(\mathrm{r}_{\mathrm{t}}\right)$ are uncorrelated but are not i.i.d also we can notice time varying $\sigma_{2 \mathrm{t}}$ which lead to fatter tails, this relatively to a normal distribution (Campbell, Lo, \& Mackinaly, 1997). The second model is Garch model, we notice in Arch $(1,1)$ next periods variance only depends on last periods squared residuals, an Arch $(1,1)$ model is an Arama $(1,1)$ model, so the crisis that caused a large residual would not have the sort of persistence this led to an extension of the Arch model to a Garch generalized Arch model which developed by Bollerslev (1986):

$$
\sigma_{2}=a_{0}+b_{1} a_{2 t-1}+b_{2} \sigma_{2 t-1}
$$

Where: $a_{0}>0, a_{1}>0, b_{1}>0$ and $a 1+B_{1}>1$, for this process the forecast of variance is a blend, and if data is stationary var $\left(a_{1}\right)$ can be written as:

$$
\operatorname{Var}\left(a_{t}\right)=C_{0} / 1-a_{1}-b_{1}
$$

A Garch $(1,1)$ model written as follow:

$$
\begin{aligned}
\sigma_{2 t} & =C_{0}+a 1 a_{2 t-1}+C_{0} B_{1}+a_{1} B_{1} a_{2 t-2}+B_{1} 2\left(C_{0}+a 1 a 2_{t-3}+b_{1} \sigma_{2 t-3}\right) \\
& =C_{0} / 1-B_{1}+a_{1} \sum a_{2 t-1}-I b_{1 i}
\end{aligned}
$$

Rewrite the Garch $(1,1)$ equation as:

$$
\sigma 2 t=\left(1-a_{1}-B_{1}\right) E\left[\sigma_{2 t}\right]+a_{1} a_{2 t-1}+B_{1} \sigma_{2 t-1}
$$

As this model Garch $(1,1)$, conditional variance is a weighted combinanation of the unconditional variance of returns. From the $1^{\text {st }}$-step a head variance forecast we can notice that $\left(a_{1}+B_{1}\right)$ determines how quickly the variance forecast converges to the conditional variance. If the variance spikes up during a crisis, we can measure the half life which given by:

$$
K=\ln \left(a_{1}+B_{1}\right) K / L N\left(a_{1}+B_{l}\right)
$$

This indicates the forecast and the conditional variance, where $\mathrm{k}$ indicates for number of periods. The question which rises up how implied volatility react asymmetrically to up and down stock market moves; in this case we 
should use other index which measure the weighted average of the implied volatility of short term of the stock market.

We cannot give a clear interpret for why volatility should increase more than the level of stock market prices drop compared to a stock price rise, in other hand as stocks drop, the debt/equity ratio increased and stock become more volatile with higher leverage ratio, the leverage could be explain the changes in volatility associated with stock market are much larger than that which could be explain by leverage Glosten, Jagannathan and Runkle (1993) has an account the asymmetric model of Garch model called GJR-Garch model, also known as T-Garch (Threshold) which can be written as:

$$
\sigma_{2 t}=C_{0}+a_{1} a_{2 t-1}+\gamma_{1} S_{t-1} a_{2 t-1}+B_{1} \sigma_{2 t-1}
$$

We can estimate $\gamma 1$ by using maximum likelihood techniques, another variant Garch model to account for a symmetry known as E - Garch $(1,1)$ model by Nelson $(1991)$, and can be written as:

$$
\ln \left(\sigma_{2 t}\right)=C_{0}+a_{1} a_{2 t-1}+\gamma_{1}\left(a_{1 t-1}\right)+B_{1} \ln \left(\sigma_{2 t-1}\right) / a_{1 t-1}
$$

Another variation of a Garch model known as Garch $(1,1)-\mathrm{M}$, which tests whether variance can impact the mean of future returns.

\section{The Model of the Study}

Many reasons that let us to forecast volatility, first to hold the risk of holding shares, then to forecast confidence intervals of data, thus accuracy of intervals can be got accurate variance of the errors, third, more efficient results demonstrate if Heteroscedasticity is captured properly. Thus the co variance of the returnee of stock market is modeled as a function of the past values of other independent variables and as exogenous variables, therefore the Arch (1) modeled two distinct specifications one for the conditional mean and other for the conditional variance. We can define Garch-M which introduces conditional variance in mean (Engle, Lillian, \& Robins, 1987) as:

$$
Y_{t}=X t \gamma+\sigma_{2 t} \gamma
$$

This is a variant of the Arch-M specification, in equation (10) we use the conditional standard deviation, where the expected return on assets is related to the expected coefficients of risk as a measure of return trade off.

An Arch mode, 1 if we assume the return of ASE stock market on asset is:

$$
R t=\mu+\sigma_{2 t \dot{t} t}
$$

Whether: ćt is distributed as $\mathrm{N}(0,1)$ i.i., the residual of returns are defined as:

$$
\dot{\alpha}_{t}=\sigma_{2 t \varepsilon ́ t}
$$

Engle (1982) has developed Arch (1) model, which can be written as:

$$
\sigma_{2 t}=\dot{\alpha}_{0}+\dot{\alpha}_{1} \dot{\alpha}_{2 t-1}
$$

The kurtosis of át is defined in normal distribution, the kurtosis of 3 :

$$
\text { Kurtosis (at) }=3 E\{\sigma t 4\} / E\{\sigma 2 t\} 2
$$

If the data is stationary, the $\operatorname{var}(a t)=\operatorname{var}\left(a_{t-1}\right)=e\left(a_{2} t-1\right)$.so

$$
\operatorname{Var}\left(a_{t}\right)=a_{t} / 1-a_{1}
$$

ARMA (1) model on squared residuals which can be written as:

$$
\mathrm{a}_{2 \mathrm{t}}=\mathrm{C}_{0}+\left(\mathrm{a}_{1}+\mathrm{B}_{1}\right)_{\mathrm{t}-1}+\mathrm{vt}-\mathrm{B}_{\mathrm{t}} \mathrm{v}_{\mathrm{t}-1}
$$

due to a stationary process let us to write the model as follow:

$$
\operatorname{Var}\left(a_{t}\right)=C_{0} / 1-a_{1}-B_{1}
$$

$\operatorname{ARMA}(1,1)$ model can be considered as AR $(\infty)$, and Garch $(1,1)$, the model can be can be written as follow:

$$
\sigma_{2 t}=C_{0}+a_{1} a_{2 t-1}+B_{1} \sigma_{2 t-1}
$$

And as the substitution:

$$
C_{0} / 1-B_{1}+a_{1} \sum a_{2 t-1}-i B_{i}
$$

From this model $\left(\sigma_{2 t-1}\right)$, it is clear that not only does the magnitude of $\left(\mathrm{a}_{2 \mathrm{t}}\right)$ effect future volatility, but the sign of $\left(a_{t}\right)$, also effect of future volatility at least for equities, it is not clear why volatility should increased during the period of the level of stock returns rise, and when stock returns dropped down, the ratio of debt to equity and returns of stock of ASE increases and becomes with it is higher leverage more volatile.

The threshold Garch (T-Garch) model can be written as (Golsten et al., 1993) as follows: 


$$
a_{2 t}=C_{0}+a_{1} a_{2 t-1}+b_{1} S_{t-1} a_{2 t-1}+B_{1} \sigma_{2 t}
$$

if: $\left\{\mathrm{a}_{\mathrm{t}-1}<0\right\}$ or $\left\{0\right.$, if $\left.\mathrm{a}_{\mathrm{t}-1}>0\right\}$

The mean variance of returns of ASE can be impacted by the variations of Garch model, the model can written as:

$$
\sigma_{2 t}=C_{0}+a_{1} a 2_{t-1}+B_{1} \sigma_{2 t-1}
$$

Therefore, it appears that volatility is more than the mean of variance of ASE returns.

\section{Data and Methodology}

\subsection{Data}

The data related to Amman stock exchange daily observation of Amman stock index from 21/12/1994 to $31 / 6 / 2013$ which represents daily observation to estimate and forecast these results of observation indices, E-views 5 is used as a package to analyze the data by using Arch and Garch models also the QML technique used to estimate the volatility, this technique is which proposed by Bellerslev and Wooldridge (1992), therefore we can use the daily returns of stock market of Amman stock, and confirm it is significant as Johnston and Dinardo (1997). Table 2 shows descriptive statistics for logarithm differences of returns.

Table 2. Descriptive statistic the daily returns of ASE*

\begin{tabular}{lllllll}
\hline Index & Average & Min & $\max$ & Std.dev & kurtosis & skewness \\
\hline ASE & .07323 & -9.2535 & 8,654 & 2.3421 & 4.3224 & -0.5443 \\
\hline
\end{tabular}

Note. Logarithm differences. 100 (ln rt- rt-1).*

We simulate stock prices $\mathrm{pt}$ from the relation $\mathrm{pt}=\mathrm{e} \mathrm{rt} \mathrm{p}_{\mathrm{t}-1}$ is return series generated from the fitted models by taking boot strap steps 1, 2 also we present the parameter estimates of Garch $(1,1)$ and Garch $(1,2)$. Table 3 shows the results as stationary condition holds for the models.

\begin{tabular}{|c|c|c|c|c|c|}
\hline Period one & $\gamma$ & A1 & A2 & $\mathrm{B} 1$ & $\mathrm{~A} 1+\mathrm{B} 1 \sum$ \\
\hline $\operatorname{Garch}(1,1)$ & .000254 & .1892 & -------- & 4558. & \\
\hline $\operatorname{Garch}(1,2)$ & .0005672 & .1543 & .7435 & .5081 & .8532 \\
\hline \multicolumn{6}{|l|}{ Period two } \\
\hline $\operatorname{Garch}(1,1)$ & .007483 & .06531 & -------- & .6327 & .7546 \\
\hline $\operatorname{Garch}(1,2)$ & .0000601 & .05634 & .03128 & .7813 & .8924 \\
\hline
\end{tabular}

Table 3. Two periods of data Garch tests results

\subsection{Discussion}

Respectively to Table 3 results, it can be observed that both Garch $(1,1)$ and Garch $(1,2)$ models fit the data, the Garch $(1,1)$ not $t$ clearly estimate the superior performance to Garch $(1,2)$, thus we fund Garch $(1,1)$ was adequate to capture most of the conditional heteroskaedsiticity. As daily stock returns may be correlated with the day-of-the week effect, therefore I have filtering the daily means and variances using the OLS method to fitted value of rt from regression results, hence we can write the the model as :

$$
R_{t}=a_{1} \text { Sunt }+a_{2} \text { Mont }+a_{3} \text { Tuet }+a_{4} \text { Went }+a_{5} \text { Thurt }+ \text { et }
$$

Return on Sunday, Monday, Tuesday, and Wednesday, Thursday and per time on Sunday. The result of regression is stated in Table 4. 
Table 4. OLS result of daily return for the sample period of ASE

\begin{tabular}{lllll}
\hline Days & Mean & S,Error & Variance & S,Error \\
\hline Sunday & $.234^{*}$ & .0284 & $* 4.6342$ & .365 \\
Monday & .0921 & .231 & $.752^{* *}$ & .274 \\
Tuesday & .0832 & .437 & $1.3871^{* *}$ & .187 \\
Wednesday & .05233 & .342 & $1.7452^{* *}$ & .1978 \\
Thursday & $.0294-$ & .254 & $1.2354^{*}$ & .1875 \\
\hline
\end{tabular}

Note. Significant * at 5 percent level; ** significant at 10 percent level.

Unit root test to data has employed to analyze the data to insure of normal distribution, thus Table 5 shows the results.

Table 5. Root tests by ADF and PP

\begin{tabular}{lllll}
\hline $\mathrm{ADF}$ & $\mathrm{PP}$ & Lags & $10 \%$ & $5 \%$ \\
\hline$-2.3672 * *$ & $-13.524 * *$ & 23 & -1.740 & -2.4523 \\
\hline
\end{tabular}

Note. $* *$ at $5 \%, 10 \%$ level significance.

In Table 5 results a unit root test were carried out, Augmented dicky-fueleir and Philips Peron test, the lag length in the ADF case and the truncation lag in the PP case are chosen on the basis of the sample of autocorrelation function of returns, the lag is chosen as the highest one, for which this autocorrelation is significant provided this is less than $\sqrt{ } \mathrm{N}$. From the table results clearly null hypothesis is rejected of a unit root against of the trend - stationary of alternative hypothesis. Table 6 shows the autocorrelation of squared standardized residuals of Amman stock market returns, we have notice that autocorrelation are decay and reduced from lagged to other in ASE portfolio returns autocorrelations, therefore we have test the data to find p-values at level $5 \%$ of significant to insure of hypothesis as to reject or accept the null hypothesis of residual of model, enhance to forecast the standard mean deviation for the next day which as a result is 0.0246 , which are not very closed to normal distribution, the fat tails of the return distribution is determined through the analyses. Table 6 shows the autocorrelation of squared portfolio returns, that it dies quickly to zero from the $5^{\text {th }}$ lags and all observations are significant due to prob level, the value of risk exceeded; meaningfully, a slightly conservative estimation of the result.

Table 6. Autocorrelation of squared standard residuals of AMS returns

\begin{tabular}{llll}
\hline Lags & AC & Q- Stat & Prob \\
\hline 1 & .0234 & .4322 & .721 \\
2 & .0167 & 2.3416 & .236 \\
3 & -.034 & 3.5431 & .233 \\
4 & -.023 & 3.5432 & .296 \\
5 & .0127 & 4.5632 & .453 \\
6 & -.0189 & 4.9843 & .409 \\
7 & -.0219 & 5.1234 & .653 \\
8 & -.0227 & 5.3576 & .543 \\
9 & -.0093 & 5.9832 & .543 \\
10 & -.0231 & 6.4322 & .845 \\
11 & -.0153 & 6.8967 & .543 \\
12 & -.0121 & 8.4325 & .436 \\
\hline
\end{tabular}




\begin{tabular}{llll}
\hline 13 & -.0076 & 9.3210 & .765 \\
14 & -.00765 & 10.234 & .845 \\
15 & -.0119 & 12.324 & .765 \\
\hline
\end{tabular}

Note. Data Autocorrelation used 15 lags.

According to Table 7 the sample kurtosis $\mathrm{R}_{\mathrm{t}}$ is 3.5648 and 5.01342 , the skewness are -0.3272 and -0.5786 .

Table 7. Descriptive statistics for standardized yearly returns of ASE

\begin{tabular}{lllll}
\hline & St $/$ dev & Kurtosis & Sekwness & Jarque-Berra stat \\
\hline ASE & .7544 & 3.5648 & -.5786 & 34.65 \\
\hline
\end{tabular}

Suppose that we apply different models, we should decide which model is best model to be our target in use of our results? Simply to answer this question, whether the parameters of data variables estimated by the two models, the maximum likelihood values should be compeered, but if the models differ in their parameters, the Akaike information criterion, (AIC) can be used to emphases which model is best to fit the data, and adjustment to the equation of likelihood;

$$
\text { Aic }(p)=2 \ln (\text { maximum likelihood })-2 p
$$

Where: $\mathrm{p}$ indicates to numbers of estimated parameters in the model. The OLS estimate of two regression models shows that the parameters of indices are positive significant of daily mean of ASE returns, I have estimate the effect by standardized the daily returns using the below function :

$$
R t=(r t r t) \sqrt{ } \pi l
$$

Where: $\pi 1$ indicates to $(\mathrm{rt}-\mathrm{rt})^{2}$.

Table 7 shows the descriptive statistics for standardized yearly returns of ASE.

Returns (rt), are thus the normalized to zero mean and unit variance. According to table results of Jarque-Berra it indicates to normal distribution.

The second criterion attributed to Schwartz criterion (SBC), it demonstrated in our research here as:

$$
S B C(P)=2 \ln (\text { maximum likelihood })-p \ln (T)
$$

P: parameters in the model, and T: number of observations in the model. A common test has performed on et is the portmanteau test, which jointly test whether several squared autocorrelations of et are zero. The test statistics are proposed by Box and Pierce (1970) which preformed as:

$$
Q(M)=T \sum P I 2
$$

Ljung and Box (1978) can use to asmmal sample size data as our data in this paper as:

$$
Q(M)=T(T+2) \sum P I 2 /(T-1)
$$

$\mathrm{m}$ : represents number of autocorrelations, and $\mathrm{T}$ represents number of observation in the model. When we are looking at Garch models, therefore I have analyzed the densities setting these quantities of data to their unconditional expected values to avoid the recursive evaluation of maximum likelihood on the unobserved values. Results are available in Table 8 .

The models above in Table 9, are described two moments of the series in the dynamic form which proposed by Box-Pierce method, the stationary constraints observed for each model. According the results of table we can demonstrated that CO-Garch is the best choice due to small amount results in AIC and SBC also as the skewed. Forecasting analysis for return index is made in Table 9 to compare densities. And for every density all models are non significant at 5 percent level, these values suggests long persistence of the volatility for the indices, the skewed student —distribution shows results that are superior to the symmetric $t-$ student and log likelihood ratio is too large scale, thus it is necessary to add a symmetric Garch models. to have a results of compare between densities, E-Garch out performs, and CO-Garch are provides poorest forecasts, while Garch method gives less satisfied results than other models, while E-Garch gives better forecasts. 
Table 8. ASE portfolio data analysis

\begin{tabular}{|c|c|c|c|}
\hline & Normal & Students & Skewed \\
\hline & Arch & Garch & Co-Garch \\
\hline $\mathrm{Q}(20)^{*}$ & 25.435 & 25.432 & 24.432 \\
\hline Q $2(20)^{*}$ & 21.678 & 27.875 & 25.765 \\
\hline $\mathrm{P}(100)^{* *}$ & 56.879 & 48.654 & 43.213 \\
\hline Prob (1) & .0987 & .521 & .453 \\
\hline Prob (2) & .043 & .215 & .217 \\
\hline $\mathrm{AIC} * * *$ & 2.432 & 2.234 & 2.156 \\
\hline $\mathrm{SBC} * * *$ & 3.786 & 3.354 & 3.015 \\
\hline Log likelihood & -26328.870 & -2461.250 & -2732.61 \\
\hline
\end{tabular}

Table 9 indicates to compare between different models to show which model can be best model for data.

Table 9. Forecasting analysis for returns of ASE

\begin{tabular}{|c|c|c|c|c|c|c|}
\hline & Garch student- $t$ & Garch skewed & E-Grach t-student & E-Grach Skewed & CO-Garch t-student & CO-Garch skewed \\
\hline MSE (1) & .312 & .328 & .345 & .432 & .346 & .376 \\
\hline $\operatorname{MSE}(2)$ & ,458 & .398 & .326 & .405 & .532 & .412 \\
\hline Med SE (1) & .0398 & .0365 & .0459 & .0459 & .0354 & .0387 \\
\hline Med SE (2) & .352 & .251 & .281 & .276 & .248 & .249 \\
\hline MAE (1) & .298 & .287 & .288 & .247 & .291 & .286 \\
\hline MAE (2) & .498 & .541 & .556 & .532 & .543 & .452 \\
\hline RMS (1) & .432 & .598 & .512 & .532 & .516 & .452 \\
\hline RMS (2) & .597 & .867 & .645 & .652 & .675 & .679 \\
\hline AMA PA (2) & .674 & .753 & .834 & 875. & 0.839 & .876 \\
\hline TH.I (1) & .675 & .786 &, 764 &, 832 & .832 & .875 \\
\hline TH.I (2) & .543 & .523 & .438 & .521 & .512 & .532 \\
\hline
\end{tabular}

Note. (1): indicates to mean equation. (2): indicates to variance equation.

In models skewed distribution, all models has good results in forecasting ASE mean of conditional variance, thus we can concluded that the skewed of data densities is more appropriate for molding ASE, thus it gives good signs of forecasting the data. Table 10 illustrate results of ASE portfolio and frontiers.

Table 10. Forecast ASE portfolio by using BL approach

\begin{tabular}{ll}
\hline Portfolio indicators & Ratios \% \\
\hline Returns & .6732 \\
Alpha & -0.4323 \\
Risk & .4342 \\
Sharp ratio & 1.3212 \\
Tracking error & 2.1345 \\
\hline
\end{tabular}


Finally the parameters estimate of Garch $(1,1)$ and Garch $(1,2)$ presents in Table 11.

Table 11. Garch (1) and Garch $(1,2)$ results

\begin{tabular}{llllll}
\hline Models & $\omega$ & $\alpha$ & $\alpha$ & в 1 & + B $1 \sum \dot{\alpha} 1$ \\
\hline Garch $(1,1)$ & .003421 & .1234 & $\ldots \ldots \ldots$ & .50654 & .6784 \\
Garch $(1,2)$ & .004189 & .14327 & .06745 & .57681 & .6759 \\
\hline
\end{tabular}

As the stationary discussed $\sum \dot{\alpha} 1+\mathrm{B} 1$ in both model are all less than one, though rather close to, the stationarity condition holds for the fitted model. The comparative plots of two simulated models almost coincide, conforming again, thus the difference between models performance is too small, thus mainly I decided to choose Garch $(1,1)$ in analysis the volatility. Finally volatility should be estimated, this is presented in Table 12 .

Table 12. Volatility as single regime model and restricted regime model

\begin{tabular}{llll}
\hline & Single regime model & Low volatility regime & Average return \\
\hline Volatility increases & -0.654 & $\ldots \ldots \ldots \ldots \ldots \ldots$ \\
Volatility reductions & -0.632 & $\ldots \ldots \ldots$ & $\ldots \ldots \ldots \ldots . \ldots$ \\
Threshold & 27.05 & $\ldots \ldots$ & $\ldots \ldots \ldots . \ldots$ \\
Low volatility regime : & & & -1.365 \\
Volatility increases & & -0.654 & 0.786 \\
Volatility reductions & & .453 & 786.53 \\
Restricted regime ( one regime ) & 157.98 & & \\
\hline
\end{tabular}

According to results of table the single regime model of volatility has a negative sign thus the relationships is inverse relation, when the volatility increases and also when there is reduction, also in single regime model threshold is 29.3 , the average of return has inverse relation with the effected variables when the volatility increases, but proportional relationship when the volatility reductions. Lastly I have estimated the Sunday effect in ASE by the conditional mean of variance function through comparison results of analysis week of ASE which start on Sunday and end on Thursday, the result is stated in Table 13.

Table 13. Test for the sunday effect in ASE daily returns

\begin{tabular}{|c|c|c|c|c|c|c|c|c|}
\hline Day of week & Sun $\alpha 1$ & Mon ó2 & Tues $\alpha \dot{3}$ & Wed $\alpha$ 4 & Thurs ó 5 & $\omega$ & $\gamma$ & в1 \\
\hline Mean equation & & & & & & Variance & Equati & on \\
\hline Coefficient & -.084 & -.062 & -.083 & -.094 & -.068 & .043 & .21 & .47 \\
\hline Standard Error & .42 & $(.072)$ & .067 & .063 & .32 & .00 & .00 & .032 \\
\hline
\end{tabular}

Note. $\omega, \mathrm{B} 1$, and $\gamma \mathrm{N}: \mathrm{B}$ are the coefficients of variance equation.

The model which used to determined the results is Garch model $(1,2)-\mathrm{M}$, as results the effect of Sunday as opening day of sell and buy clearly has negative sign but not largely than other days due to aware of dealer in ASE, and they are not deal to much in first day of their week, they are wait to other days as individual expectations and waiting for more information of good news or bad news.

\section{Concluded Remarks}

This paper enriched the empirical work by accommodating the following issues, first it adjusts for sample size and long period of study which extended from January 1996 up to June of 2010, also indicates volatility shocks of time-series, partial and autocorrelations, second I have analyze the daily return pattern and Sunday effect, thirdly, it utilized from some measurement errors hypothesis in different models as compression to choose the best model for analysis the data. Therefore this paper is designed to investigates and analyze the volatility of 
ASE stock market returns using the daily returns for the period under investigation, for achieving this purpose, the Arch, Garch, CO-Garch are employed to data analysis in hence of the procedure I have used Arch and Garch models to capture symmetric effects, whereas the other models are employed to capture the asymmetric effects, the data of returns as daily returns or yearly returns showed both of (volatility clustering), this paper was built on four hypothesis, the first hypothesis was to examine the volatility through using different models, second hypothesis was to capture a symmetric effect through these models, thirdly was to check whether the BL approach can determined the volatility and asymmetric volatility, the forth hypothesis is to test for which model can be decisive the best model to analyze the data. I have fund that returns are volatile and that has a positive shocks on daily data and yearly returns, also I have fund that volatility response to shocks tends to positive in ASE. Although the Garch model $(1,1)$ and Garch $(1,2)$ are fund that it can display asymmetric effects, and it was better than other models, due to the log likelihood ratio and to other diagnostic test such as kurtosis, skewed, and lower statistics of Jerque and Berra statistics.

The ASE not follow a random walk over the period Jan, 1996 to June, 2010, this can be explain the market capitalization and liquidity, capitalization average gives an evidence as 128\% than the last periods (1990-1996), also we can add that due to non-restricted movement of capitalization as ASE an opening-up of the market. In addition to these results the daily returns and yearly exhibit significant non-linear decency, while the daily returns from the ASE do not confirm to a random walk.

These results is consistent with previous studies results documented in the literature, such as the positive significant of Sunday effect of daily return, and the ASE do not confirm to a white noise.

\section{References}

Alexander, G. (2001). Orthogonal Garch, chapter 2. In C. Alexander (Ed.), Mastering Risk (pp. 21-28). London: Financial Times Prentice Hall.

Anderson, T, G., \& Tim, B. (1998). Answering the skeptic, standard volatility models dose provide accurate forecasts. International Econometrics Review, 39, 885-905. http://dx.doi.org/10.2307/2527343

Bauwens, L., \& Strti, G. (2007). A component Garch model with time varying weights. Core discussion paper.

Black, F. (1992). Global portfolio optimization, financial analysis. Journal of Financial Analysis, 48(5), $28-43$. http://dx.doi.org/10.2469/faj.v48.n5.28

Black, F., \& Litterman, R. (1992). Asset allocation combining investors views with market equilibrium. Journal of Fixed Income, September, 7-18.

Bollerslev, T. (1986). Generalized autoregressive conditional heteroscadesticity. Journal of Econometrics, 131, 307-327. http://dx.doi.org/10.1016/0304-4076(86)90063-1

Engle, R. (1982). Autoregressive conditional heteroscadesticity with estimates of the variance of the United Kingdom inflation. Econometrica, 50, 987-1007. http://dx.doi.org/10.2307/1912773

Engle, R. F., \& Kroner, K. F. (1995). Multivariate simultaneous generalized Garch. Econometric Theory, 11, 122-150. http://dx.doi.org/10.1017/S0266466600009063

Fan, J., Wang, M., \& Yao, Q. (2008). Modeling multivariate volatilities via conditionally uncorrelated components. Journal of the Royal Statistical Society, Series B, 70, 679-702. http://dx.doi.org/10.1111/j.1467-9868.2008.00654.x

French, K. R. (1980). Stock returns and the weekend effect. Journal of Financial Econometrics, 8, 55-70. http://dx.doi.org/10.1016/0304-405X(80)90021-5

Glosten, L. R., Janoannathan, R., \& Runkle, D. E. (1993). Relationship between the expected value and the volatility of the nominal excess return on stocks. Journal of Finance, 48, 1779-1801. http://dx.doi.org/10.1111/j.1540-6261.1993.tb05128.x

Green, W. (1997 ). Econometrics Analysis (3rd ed.). New Jersey: Prentice-Hall.

Hafner, C. (2008). Temporal Aggregations of Multivariate Garch Processes. Journal of Econometrics, 142, 467-483. http://dx.doi.org/10.1016/j.jeconom.2007.08.001

Halan, M. (2002). Asymmetric Garch models for Jordanian stock returns. Abhath Al-Yarmook, Basic Science and Engineering, 11, 155-181.

International Monetary Fund. (2003). International Financial Statistics, 61.

Jerque, C., \& Berra, A. (1987). A test for normality of observations and regression residuals. International 
Statistical Review, 55, 163-172. http://dx.doi.org/10.2307/1403192

Lumbert, P., \& Laurent, S. (2001). Modeling Financial Time Series Using Garch-Type Models and a Skewed Student Density. Mimo, Universities de liege.

Lumbert, P., \& Laurent, S. (2006). Modeling Skewness Dynamics in Series of Financial Data. Discussion paper, Institute de statisique, Lounvain, Neuve.

Maekawa, S. L., \& Tokutsu, Y. (2005). A Note on Volatility Persistence and Structural Changes in Garch Models. Technical Report, University of Hiroshima.

Nelson, D. B. (1991). Conditional heteroscadestisity in asset returns; a new approach. Econometrica, 59, 347-370. http://dx.doi.org/10.2307/2938260

Pagan, A. R., \& Schwartz, G. W. (1990). Alternative models for conditional stock volatility. Journal of Econometrics, 45, 267-290. http://dx.doi.org/10.1016/0304-4076(90)90101-X

Ryoo, H. J., \& Smith, G. (2002). Korean stock prices under limits, variance ratio tests of random walks. Applied Econometrics, 12, 545-553.

Schwartz, G. W., \& Poul, J. S. (1990). Heteroskedasiticity in stock returns. Journal of Finance, 4, 1129-1155.

Tim, B. (2008). Glossary to Arch and Garch. Creates Research Paper, 2008.

Van der Wide, R. (2002). GO-Garch: A multivariate generalized orthogonal Garch model. Journal of Applied Econometrics, 17, 549-564. http://dx.doi.org/10.1002/jae.688

\section{Copyrights}

Copyright for this article is retained by the author(s), with first publication rights granted to the journal.

This is an open-access article distributed under the terms and conditions of the Creative Commons Attribution license (http://creativecommons.org/licenses/by/3.0/). 